ARTICLE

DOI: $10.1038 / s 41467-017-00679-1$

\title{
Photo-triggered solvent-free metamorphosis of polymeric materials
}

\author{
Satoshi Honda (i) ${ }^{1} \&$ Taro Toyota (iD $^{1}$
}

Liquefaction and solidification of materials are the most fundamental changes observed during thermal phase transitions, yet the design of organic and polymeric soft materials showing isothermal reversible liquid-nonliquid conversion remains challenging. Here, we demonstrate that solvent-free repeatable molecular architectural transformation between liquid-star and nonliquid-network polymers that relies on cleavage and reformation of a covalent bond in hexaarylbiimidazole. Liquid four-armed star-shaped poly ( $n$-butyl acrylate) and poly(dimethyl siloxane) with 2,4,5-triphenylimidazole end groups were first synthesized. Subsequent oxidation of the 2,4,5-triphenylimidazoles into 2,4,5-triphenylimidazoryl radicals and their coupling with these liquid star polymers to form hexaarylbiimidazoles afforded the corresponding nonliquid network polymers. The resulting nonliquid network polymers liquefied upon UV irradiation and produced liquid star-shaped polymers with 2,4,5-triphenylimidazoryl radical end groups that reverted to nonliquid network polymers again by recoupling of the generated 2,4,5-triphenylimidazoryl radicals immediately after terminating UV irradiation. 
iving systems utilize masterfully designed molecular systems to maintain biological activities. For example, sea cucumbers are interesting because some species can switch their body into a liquiform state when removed from seawater but revert to their original state following re-immersion in seawater ${ }^{1}$. One possible mechanism underlying this biofunction is the crosslinking and de-crosslinking of collagen microfibrils in the extracellular matrix by the peptides tensilin and softenin ${ }^{2}$. The body of a sea cucumber is hard when collagen microfibrils are crosslinked with tensilin but becomes soft upon interaction with softenin and subsequent de-crosslinking. Sea cucumber-inspired materials with tuneable stiffness have been reported ${ }^{3}$, however, isothermal reversible liquid-nonliquid conversion (IRLNC) with artificial soft materials remains challenging.

Thermally reversible solid-liquid phase transition typically relies on molecular ordering and disordering is a common process for most organic molecules. The control of molecular ordering by photoisomerization of azobenzene-containing molecules has been described, leading to isothermal crystal melting and recrystallization in response to $\mathrm{UV}^{4-13}$. Although such commendable studies achieved solid-liquid transition with azobenzene-containing crystalline and liquid crystalline small molecules, these molecules do not exhibit tuneable elasticity. In contrast, the diverse range of polymers synthesized to date exhibit a wide range of tailored properties. However, attaining solid-liquid phase transition using the aforementioned mechanism seems difficult even with highly crystalline polymers because polymers are inherently a mixture of crystalline and amorphous structures. Alternatively, liquid-nonliquid conversion relying on changes in the glass transition temperature $\left(T_{\mathrm{g}}\right)$ of side-chain azobenzene-containing polymers has been reported ${ }^{14,15}$. When trans to cis photoisomerization was conducted by irradiating UV to a $\mathrm{CH}_{2} \mathrm{Cl}_{2}$ solution of the trans azobenzene-containing polymers having $T_{\mathrm{g}} \mathrm{s}$ above room temperature, the obtained cis azopolymers after the removal of $\mathrm{CH}_{2} \mathrm{Cl}_{2}$ showed $T_{\mathrm{g}}$ below room temperature, attaining liquid and nonliquid states, respectively, with the same polymers. Although such formidable systems have open the door for a repeatable photochemical molding technology, development of a smart polymer system to attain IRLNC with an alternative facile and versatile mechanism remains unexplored.

Progress in polymer chemistry allows us to synthesize various nonlinear polymers. Nonlinear polymers are expected to facilitate the realization of a methodology for tuning properties of polymers without changing their chemical composition or molecular weight ${ }^{16}$. Among a wide variety of nonlinear polymers, one basic network architecture comprises star-like components. Various network organic and polymeric materials are produced by reactions between starshaped molecules, for example, the synthesis of silica by a reaction between tetraethylorthosilicates ${ }^{17}$. In most cases, the star-shaped starting molecules in the liquid state are converted to the corresponding solid network material, but such network formation reactions are in general irreversible. To address this, we focused on a repeatable molecular architectural transformation (MAT) strategy $^{18-23}$. Various repeatable MATs, for example, linear-star ${ }^{18}$, linear-cyclic ${ }^{19-22}$, three-armed star-network ${ }^{23}$ architectures have appeared and, moreover, MAT of amphiphilic block copolymers into star and comb polymers has recently been achieved by Diels-Alder reaction ${ }^{24}$. Of various candidates exhibiting repeatable cleavage and reformation of covalent bond $s^{25}$ utilized as self-healing materials ${ }^{26}$, we focused on hexaarylbiimidazole $(\mathrm{HABI})^{27}$ as the linking point. HABI can be synthesized by the oxidation of 2,4,5-triphenylimidazoles (lophines) to generate 2,4,5-triphenylimidazoryl radicals (TPIRs) and the subsequent coupling reaction between the generated TPIRs. The TPIR is stable even under the existence of oxygen but reacts with other TPIR to generate $\mathrm{HABI}^{28}$. The covalent bond between the two imidazoles in HABI is cleavable by UV irradiation, leading to the production of a pair of TPIRs, which can recouple with each other.

Here we demonstrate a solvent-free IRLNC of poly(n-butyl acrylate) (PBA) and poly(dimethyl siloxane) (PDMS) by phototriggered repeatable MAT between star and network architectures utilizing the HABI chemistry.

\section{Results}

Photo-triggered solvent-free IRLNC by repeatable MAT of polymer materials. We envisioned that nonliquid network and a

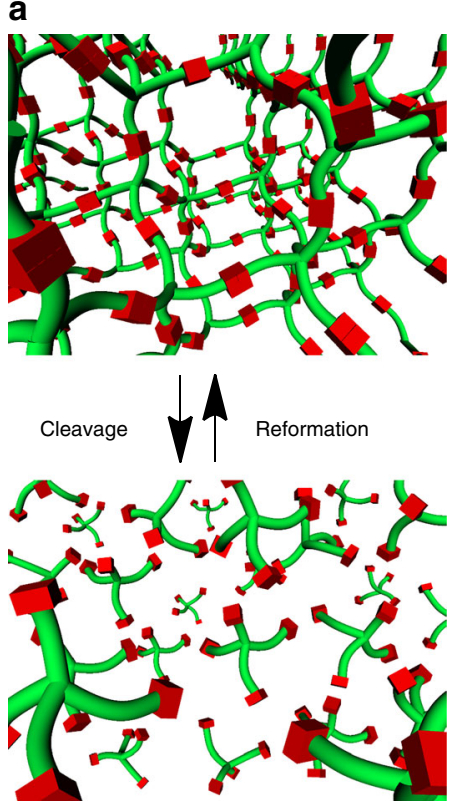

b
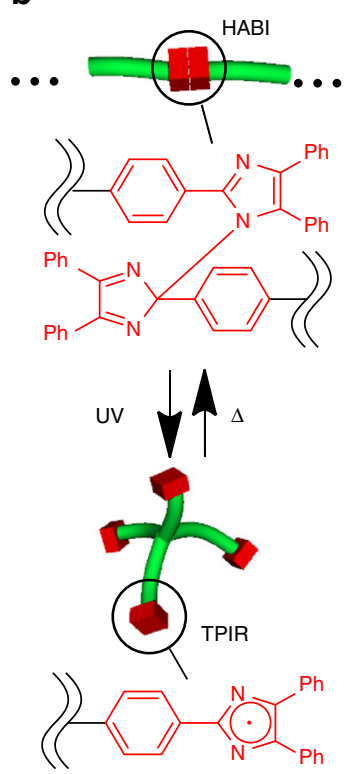

C

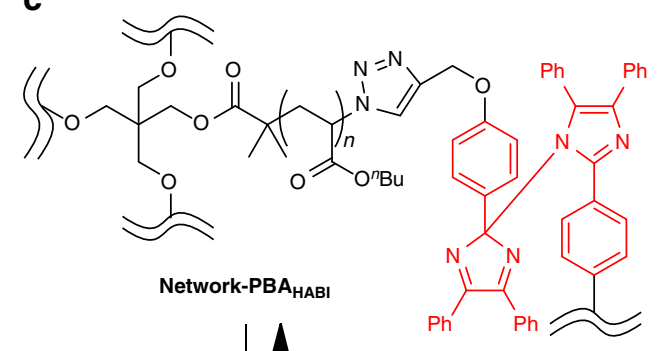

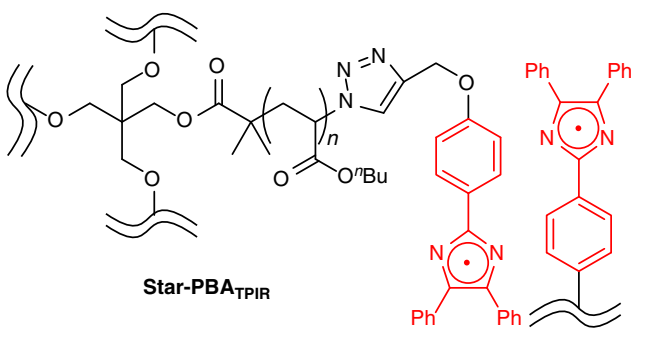

Fig. 1 Design of star-network repeatable MAT system with PBA. Schematic representation of a star-network repeatable MAT, $\mathbf{b}$ cleavage and reformation

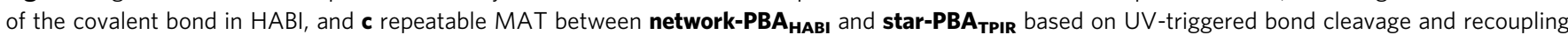


a

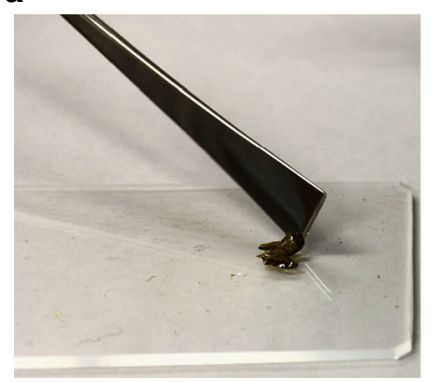

d

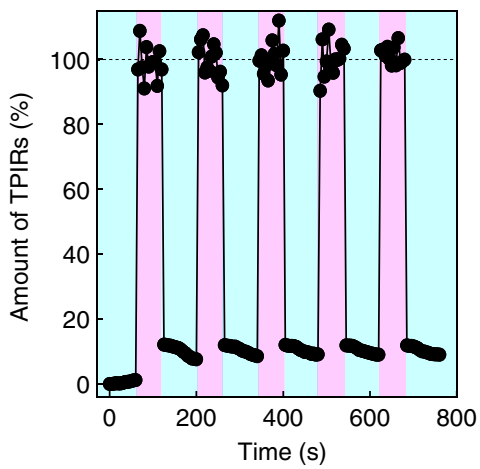

b

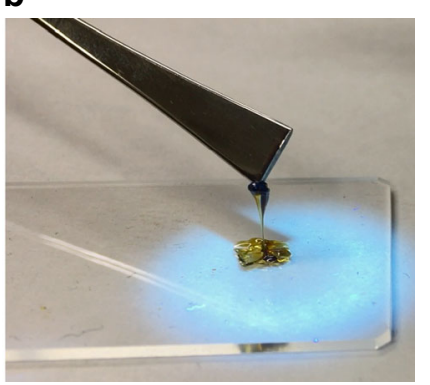

c

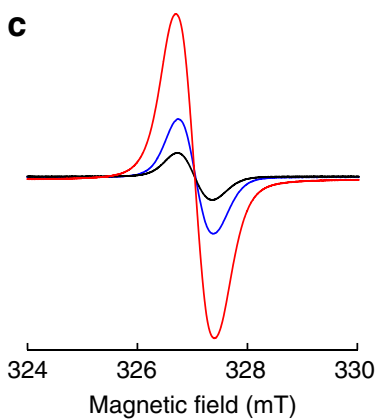

e

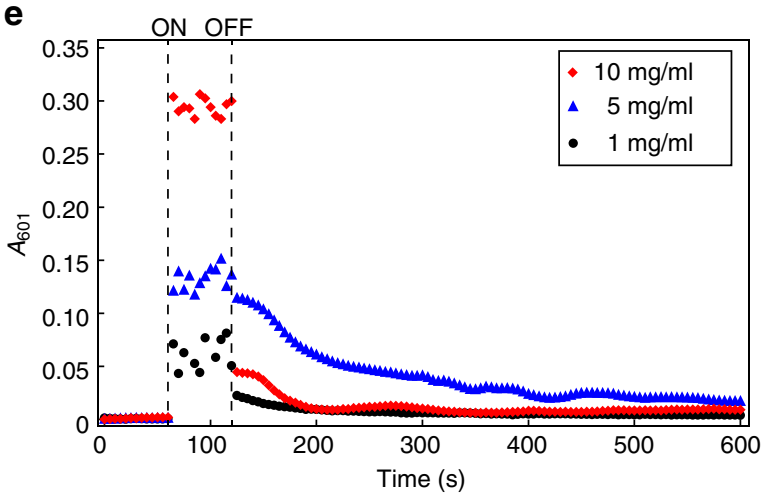

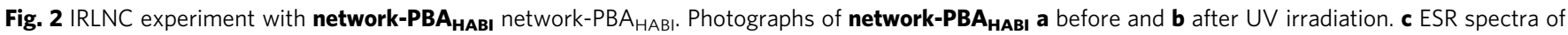

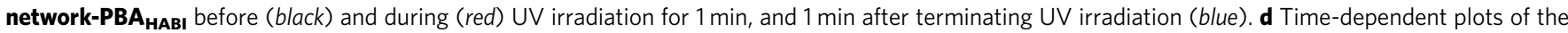
amounts of TPIR in a THF solution of network-PBA $\mathbf{A}_{\mathbf{H A B I}}(10 \mathrm{mg} / \mathrm{ml})$. The amount of TPIR was determined by recording $A_{601}$ every $5 \mathrm{~s}$. The sample was irradiated with UV and not irradiated with UV during times corresponding to the pink and light blue regions, respectively. The value of $A_{601}$ before UV irradiation was defined as $0 \%$ and the averaged $A_{601}$ during UV irradiation was defined as $100 \%$. e Time-dependent plots of absorbance at $601 \mathrm{~nm}$ for

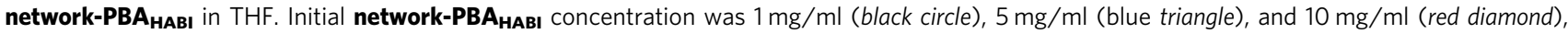
respectively. The starting (ON) and terminating (OFF) times of UV irradiation were indicated with dashed lines

liquid-star-shaped polymers can be toggled by external stimuli (Fig. 1a) and designed a repeatable MAT system relies on the cleavage and reformation of the imidazole-imidazole covalent bond in HABI (Fig. 1b). We first focused on the repeatable MAT of PBA (Fig. 1c), a common noncrystalline acrylate polymer with low $T_{\mathrm{g}}$ that is in the liquid state when its molecular weight is low. Four-armed star-shaped PBAs with bromide end groups (star$\mathbf{P B A}_{\mathbf{B r}} \mathrm{s}$ ) were synthesized by atom transfer radical polymerization of $n$-butyl acrylate initiated from pentaerythritol tetrakis(2bromoisobutyrate) (1) as the tetra-functional initiator (Supplementary Fig. 1a). Examination of the dependence of molecular weight on the state of the polymerized product revealed that an increase in the total molecular weight above $5500 \mathrm{Da}$, which corresponds to a degree of polymerization per $\operatorname{arm}\left(\mathrm{DP}_{\mathrm{n}}(\mathrm{arm})\right)$ of 8 , resulted in solidification of star- $\mathbf{P B A} \mathbf{A}_{\mathbf{B r}}$ (Supplementary Table 1). A compound with four lophines (2), which is a model small molecule for a star polymer with a $\mathrm{DP}_{\mathrm{n}}(\mathrm{arm})$ of 0 , was also synthesized (Supplementary Fig. 2). Compound 2 was a crystalline solid, and thus it was suggested that attaining IRLNC with $\mathrm{PBA}$ at least requires a $\mathrm{DP}_{\mathrm{n}}(\mathrm{arm})$ between 1-7. In the present study, star-PBA $\mathbf{A r r}_{\mathbf{B r}}$ with a $\mathrm{DP}_{\mathrm{n}}(\mathrm{arm})$ of 3 was selected for further study (Supplementary Table 1, entry 1). The four bromide end groups of star-PBA $\mathbf{B r r}_{\mathrm{Br}}$ were converted to azide groups by reacting with $\mathrm{NaN}_{3}$ and the subsequent Huisgen reaction with an ethynyl derivative of lophine (3) afforded a four-armed star-shaped PBA with lophine end groups (star-PBA $\mathbf{A}_{\text {Lophine }}$ ) (Supplementary Fig. 1a). The resulting star-PBA $\mathbf{A}_{\text {Lophine }}$ was thoroughly characterized by ${ }^{1} \mathrm{H}$ NMR (Supplementary Fig. 3a), GPC (Supplementary Fig. 4), and MALDI-TOF mass spectrometry (Supplementary Fig. 5). Oxidation reaction of the lophines followed by a coupling reaction of the generated TPIRs provided a network PBA (network-PBA HABI $_{\text {) }}$ (Supplementary Fig. 1a). The synthesized network-PBA ${ }_{\mathrm{HABI}}$ was a nonliquid material poorly soluble in common organic solvents. The ${ }^{1} \mathrm{H}$ NMR spectrum of the $\mathrm{CDCl}_{3}$ soluble part of network-PBA ${ }_{\mathrm{HABI}}$ showed that the complex signals in the aromatic region (Supplementary Fig. 3b), which did not appear before the reaction (Supplementary Fig. 3a). These signals are due to differences in the type of imidazole-imidazole covalent bond in $\mathrm{HABI}^{29}, 30$. Star$\mathbf{P B A}_{\text {Lophine }}$ and network-PBA ${ }_{\text {HABI }}$ were further subjected to ${ }^{1} \mathrm{H}$ NMR analyses using DMSO- $d_{6}$ to determine conversion yield from TPIRs to HABIs. By comparing the integration of the -NH signal at 12.5 p.p.m. appeared before (Supplementary Fig. 6a) and after the reaction (Supplementary Fig. 6b), conversion yield from TPIRs to HABIs was determined to be ca. $60 \%$.

When UV $(\lambda=365 \mathrm{~nm})$ was irradiated to the produced network-PBA $\mathrm{HABI}_{\mathrm{HA}}$ under isothermal condition at $50^{\circ} \mathrm{C}$, the

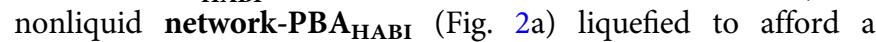
viscous material (Fig. 2b). This change was complete within $1 \mathrm{~min}$ (Supplementary Movie 1) and the material reverted to the nonliquid state within $3 \mathrm{~min}$ after terminating UV irradiation. Comparison of the ESR spectra before and after UV irradiation for $1 \mathrm{~min}$ directly demonstrated cleavage of the imidazole-imidazole covalent bond in HABI to produce a pair of TPIRs (Fig. 2c, red curve). The $g$-tensor was measured to be 2.003 , which exactly corresponded to the reported values for TPIR $^{31}, 32$. Comparison of the ESR spectra before and after UV irradiation also showed a 10 -fold increase in the amount of TPIR after UV irradiation (Fig. 2c, black and red curves). After terminating UV irradiation for $3 \mathrm{~min}$, the generated TPIRs recoupled with each other, resulting in a decrease in the relative signal intensity (Fig. 2c, blue curve). The presence of a small 
a

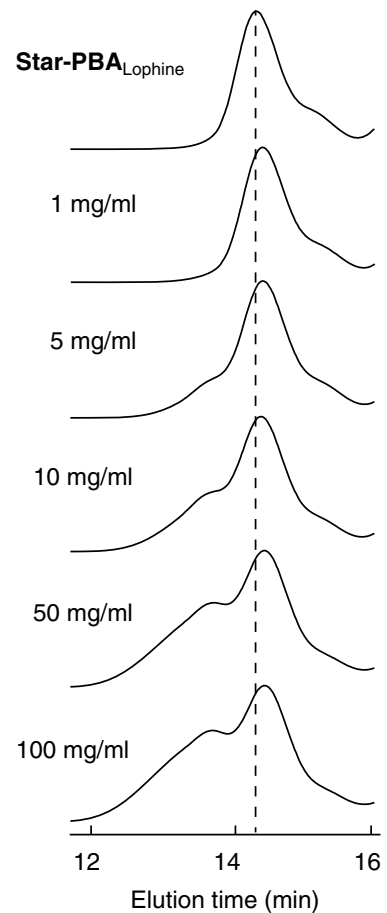

b

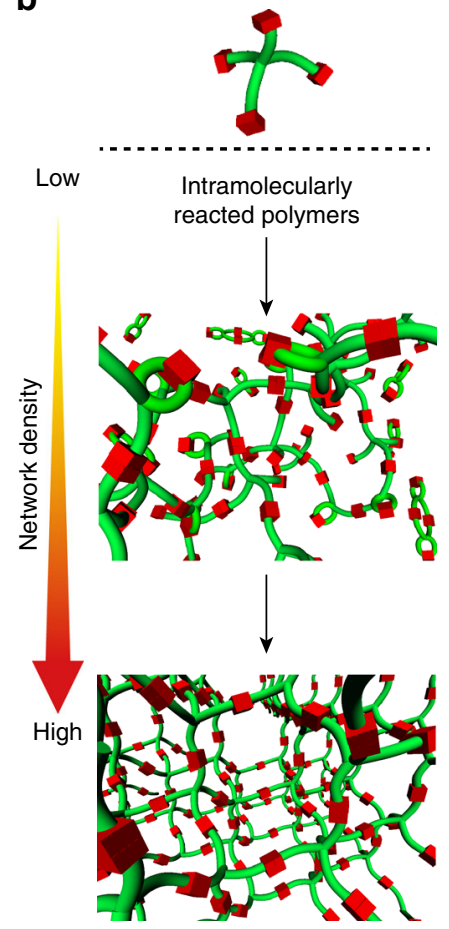

Fig. 3 Concentration-dependent repeatable MAT. a GPC traces of the products after UV irradiation to THF dispersions $(1-100 \mathrm{mg} / \mathrm{ml})$ of network-PBA $\mathbf{A}_{\mathbf{H A B}}$. $\mathbf{b}$ Schematic illustration of the dependence of the network density on concentration

amount of TPIRs before and after UV irradiation suggests that the retarded recoupling of TPIRs in the later stage of network formation reaction and that difficulty in diffusion for polymer chains in the network matrix. Nevertheless, the TPIRs and their recoupling reaction indeed functioned as an IRLNC system.

The mechanism of the reaction was investigated using three concentrations $(1,5$, and $10 \mathrm{mg} / \mathrm{ml})$ of network-PBA dispersions in THF. UV irradiation to the dispersions completely dissolved network-PBA $\mathbf{A}_{\text {HABI }}$ in THF and the solution became blue. The blue color disappeared after terminating UV irradiation for several minutes. These color changes were repeatable (Supplementary Fig. 7) and could be quantitatively monitored by absorbance at the wavelength of $601 \mathrm{~nm}\left(A_{601}\right)$ of the TPIR molecules ${ }^{33}$ by comparing the UV-vis spectra of star-PBA $\mathbf{A}_{\text {TPIR }}$ and network-PBA plots of the amount of TPIRs obtained using the networkPBA $_{\text {HABI }}$ concentration of $10 \mathrm{mg} / \mathrm{ml}$ demonstrated repetitive increases and decreases in the amount of TPIRs by turning the UV lamp on and off and most of these changes occurred within $5 \mathrm{~s}$ (Fig. 2d). Although a small amount of TPIRs remained after turning the UV lamp off for $80 \mathrm{~s}, \sim 95 \%$ of the TPIRs recoupled within $5 \mathrm{~s}$. The production of TPIRs was essentially instantaneous irrespective of concentration, but two different series of TPIR recoupling reactions were evident from the decreases in $A_{601}$ (Fig. 2e). The existence of these two trends in the decrease of absorbance at $A_{601}$ is likely due to a difference in the reaction rate between inter- and intra-molecular recoupling of TPIRs. The $10 \mathrm{mg} / \mathrm{ml}$ solution showed the apparently higher rate for the first sudden decrease in $A_{601}$ compared with the other concentrations tested (Fig. 2e). A higher concentration in general allows faster intermolecular reaction and thus the first sudden decrease in $A_{601}$ likely corresponds to intermolecular recoupling of the TPIRs. The rate of the subsequent second decreasing trend in $A_{601}(2-10 \mathrm{~min})$ is apparently slower than the first one yet is nonetheless

remarkably faster than those of recoupling reactions of typical TPIRs $(>1 \mathrm{~h})^{33}, 34$. The coupling reaction of TPIRs in dilute solution is slow because the TPIR molecules are far apart. However, similar to the bridged imidazole dimers reported by Abe et $\mathrm{al}^{35}$, the four TPIRs in the single polymer chain likely caused accelerated intramolecular recoupling of star-PBA $\mathbf{A}_{\mathrm{TPIR}} \mathrm{S}$, resulting in a faster reaction rate than those of reported ones ${ }^{33,34}$. Concentration-dependent GPC measurements were performed to test this hypothesis. Comparison of the GPC chromatograms of THF solutions containing different concentrations of networkPBA $A_{\text {HABI }}$ prepared by irradiating UV to the corresponding dispersions showed products due to the intermolecular reaction at concentrations above $5 \mathrm{mg} / \mathrm{ml}$, and these network-PBA $\mathbf{H A B I}^{-}$ derived fractions increased as the concentration increased (Fig. 3a). On the other hand, the peak molecular weights $\left(M_{\mathrm{p}} \mathrm{s}\right)$ shifted toward lower molecular weight region compared with star-PBA $\mathbf{A}_{\text {lophine, where the }} M_{\mathrm{p}}$ of star-PBA $\mathbf{A}_{\text {lophine }}$ is indicated by a dashed line in Fig. 3a. A reduction in hydrodynamic volume is a well-known effect of the formation of intramolecularly linked polymer products, for example, cyclic and eight-shaped polymers ${ }^{16}$. These results support our hypothesis regarding inter- and intra-molecular reactions and higher concentrations increased the

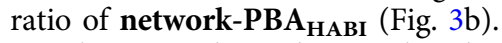

Taken together, the results demonstrate that the desired IRLNC relying on repeatable MAT has been achieved and welldefined star polymers allowed detailed analysis of the mechanism underlying the present repeatable MAT. There are several reports describing polymers with lophine side chains ${ }^{31,36}$ that characterize in detail their side-chain oxidation and UV responses; however, to achieve IRLNC with such polymers is difficult because of their inherent solidity. On the other hand, the molecular weight range of star-PBA $\mathbf{A}_{\text {Lophine }}$ and star-PBA $\mathbf{A}_{\text {TPIR }}$ compatible with maintaining the liquid state is limited, and the temperature required to demonstrate IRLNC with bulk network-

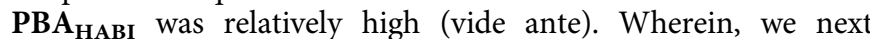
focused on the IRLNC of PDMS. Four-armed star PDMSs with hydrosilane end groups (star-PDMS $\mathbf{S i H}_{\mathbf{S i}}$ ) were synthesized by organocatalytic ring-opening polymerization of hexamethylcyclotrisiloxane $\mathrm{e}^{37}$ initiated from pentaerythritol and terminated with chlorodimethylsilane (Supplementary Fig. 1b). Subsequent hydrosilylation with 4-allyloxy benzaldehyde using Karstedt's catalyst afforded star-shaped PDMSs with aldehyde end groups

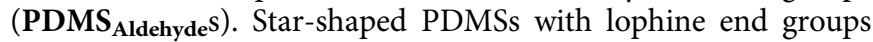
(star-PDMS lophine ) were then synthesized by the reaction of

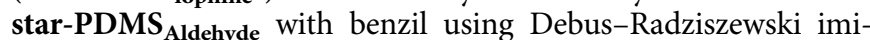
dazole synthesis conditions; subsequent oxidation to generate TPIRs followed by their coupling reaction afforded the corresponding network polymer (network-PDMS HABI $_{\text {) }}$ (Supplementary Fig. 1b). The star-shaped PDMSs were designed to have core pentaerythritol-derived branch points similar to those of starshaped PBAs to minimize the effect of the branch points on porperties. Comparison of the GPC chromatograms of star-

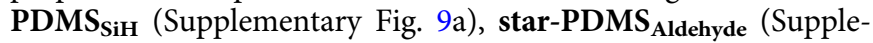

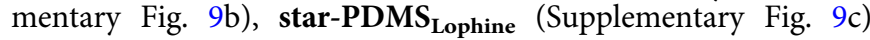
confirmed that the above-described sequential reactions did not cause degradation reactions such as cleavage of the relatively weak $\mathrm{Si}-\mathrm{O}-\mathrm{C}$ linkages. Although the molecular weight distributions of these star-shaped PDMSs were broad in comparison with those of star-shaped PBAs (Supplementary Fig. 4), the targeted star-PDMS Lophine $_{\text {was }}$ well-characterized by ${ }^{1} \mathrm{H}$ NMR (Supplementary Fig. 10a). Under the range of experimental conditions tested, the inherent liquid nature of PDMS and relatively long polymer chains prevented solidification of star-PDMS Lophine $_{\text {S }}$ despite the terminal four lophines (Supplementary Table 2). The subsequent network formation by oxidizing the terminal lophines afforded nonliquid network-PDMS HABI $_{\text {. The }}{ }^{1} \mathrm{H}$ NMR spectrum 
a

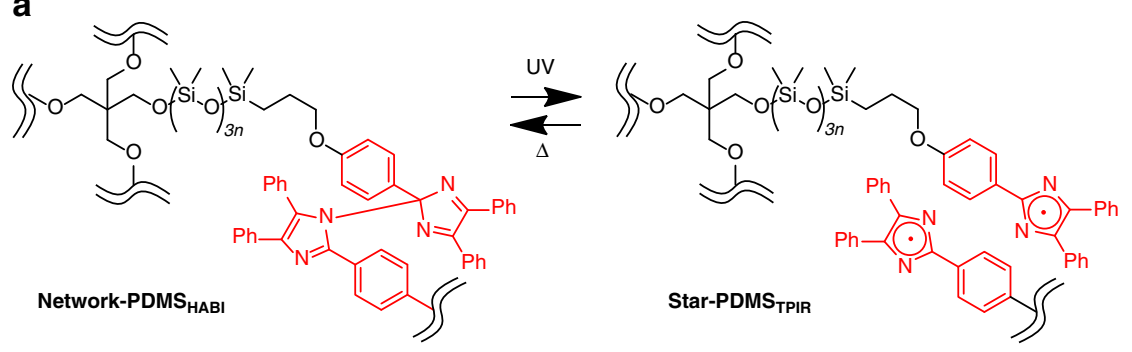

b

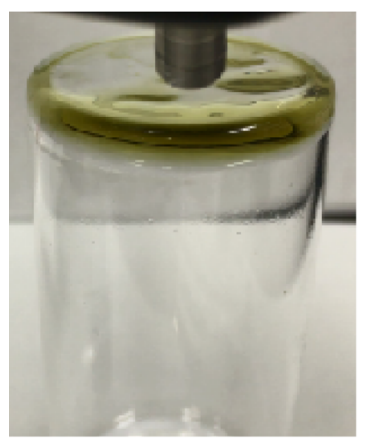

e

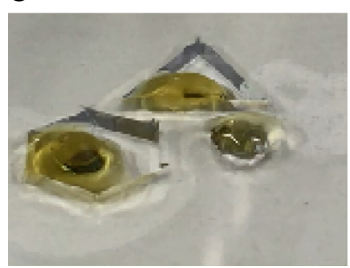

c

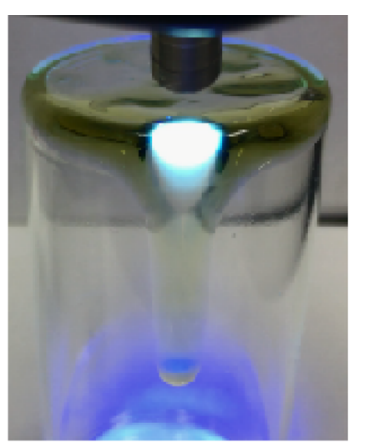

f

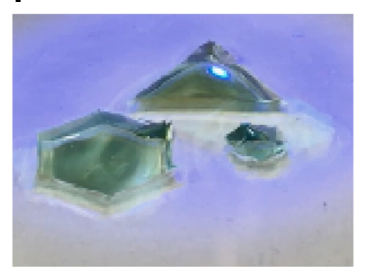

d

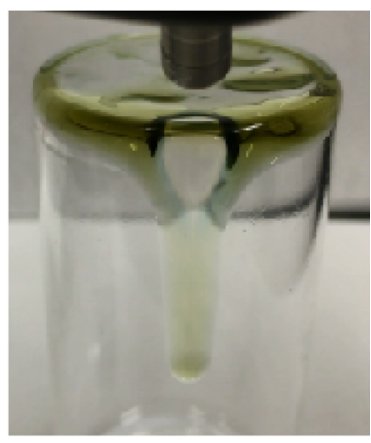

g

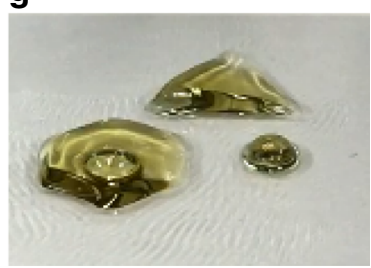

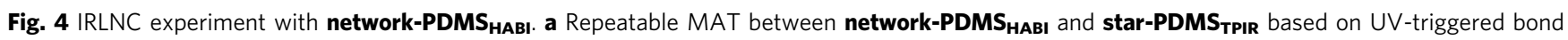
cleavage and reformation. Photographs of network-PDMS $\mathbf{S A B I}_{\mathbf{H A}}$ on the vial $\mathbf{b}$ before and $\mathbf{c}$ during UV irradiation for $3 \mathrm{~min} 43 \mathrm{~s}$ and $\mathbf{d}$ immediately after terminating UV irradiation. Photographs of network-PDMS $\mathbf{H A B}_{\mathbf{H A}}$ on the templates $\mathbf{e}$ before and $\mathbf{f}$ during UV irradiation for $9 \mathrm{~min} 55 \mathrm{~s}$, and $\mathbf{g}$ after terminating UV irradiation and removing the template plastic sheet

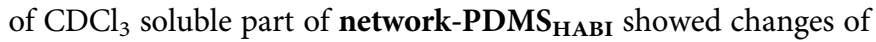
signals at the aromatic region (Supplementary Fig. 10b) similar to those recognized for network-PBA $\mathbf{H A B I}$. The conversion from TPIRs to HABIs was also determined by comparing ${ }^{1} \mathrm{H}$ NMR spectra of star-PDMS Lophine $_{\text {(Supplementary Fig. 11a) and }}$ acetone- $d_{6}$ soluble part of network-PDMS HABI $_{\text {(Supplementary }}$ Fig. 11b). The conversion yield was calculated to be ca. $70 \%$ from these spectra. The GPC chromatogram of the THF soluble part of network-PDMS ${ }_{\text {HABI }}$ showed a shift of the trace toward a higher molecular weight region (Supplementary Fig. 9d) compared with that of star-PDMS Lophine $_{\text {(Supplementary Fig. 9c), demonstrating }}$ that the TPIRs in the generated star-PDMS TPIR $_{\text {reacted }}$ intermolecularly with each other. Importantly, no lowermolecular-weight fractions were observed in the GPC chromatogram of network-PDMS ${ }_{\mathrm{HABI}}$, suggesting that the $\mathrm{Si}-\mathrm{O}-\mathrm{C}$ linkages near the junction points are stable under the reaction conditions tested and even under the existence of TPIRs.

We further attempted IRLNC based on repeatable MAT

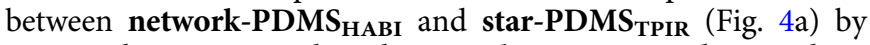
UV irradiation to nonliquid network-PDMS ${ }_{\mathrm{HABI}}$ deposited on the surface of a vial (Fig. $4 \mathrm{~b}$ ). Significantly, room temperature $\left(25^{\circ} \mathrm{C}\right)$ IRLNC was achieved (Supplementary Movie 2). The network-PDMS ${ }_{\mathrm{HABI}}$ only at the area exposed to UV liquefied and flowed down (Fig. 4c). The slight blue coloration and liquefaction of the material suggested production of starPDMS $_{\text {TPIR }}$ S. The liquid state due to star-PDMS reverted by terminating UV irradiation and nonliquid networkPDMS $_{\text {HABI }}$ reformed on the glass surface (Fig. 4d). Remarkably, the present IRLNC completed within a few minutes (Supplementary Movie 2). Furthermore, we have succeeded in applying network-PDMS HABI $_{\text {to }}$ a photochemically metamorphosing material (Supplementary Movie 3). Thus, a plastic sheet with circle, triangle, and hexagonal shaped templates was fixed on a slide glass and the network-PDMS ${ }_{\text {HABI }}$ was deposited on a surface of these templates (Fig. 4e). The nonliquid networkPDMS $_{\text {HABI }}$ on the templates liquefied upon UV irradiation and the liquefied material, that is, star-PDMS templates (Fig. 4f). After terminating UV irradiation and removing the plastic sheet with the templates, the reverted network-PDMS ${ }_{\mathrm{HABI}} \mathrm{S}$ with circle, triangle, and hexagonal shapes were formed on the slide glass (Fig. 4g). This demonstrates that the present molecular system has a potential for the repeatable photochemical molding technology ${ }^{14}$ with the different mechanism from conventional ones.

Rheological aspects of photo-triggered solvent-free IRLNC. Dynamic mechanical analysis (DMA) was performed to directly reveal the change of storage modulus $\left(G^{\prime}\right)$ and loss modulus $\left(G^{\prime \prime}\right)$ in the present IRLNC system. Time-dependent plots of $G^{\prime}$ (Fig. 5a) and $G^{\prime \prime}$ (Fig. 5b) of network-PDMS HABI $_{\text {demonstrated }}$ their repetitive decreases and increases by turning the UV lamp on and off (Fig. 5). The measurements were repeated three times (1st: black circle, 2nd: blue square, and 3rd: red triangle) and all of the measurements showed similar trends, demonstrating the reversibility of the present liquid-nonliquid conversions. More importantly, the temperature change of the material monitored 

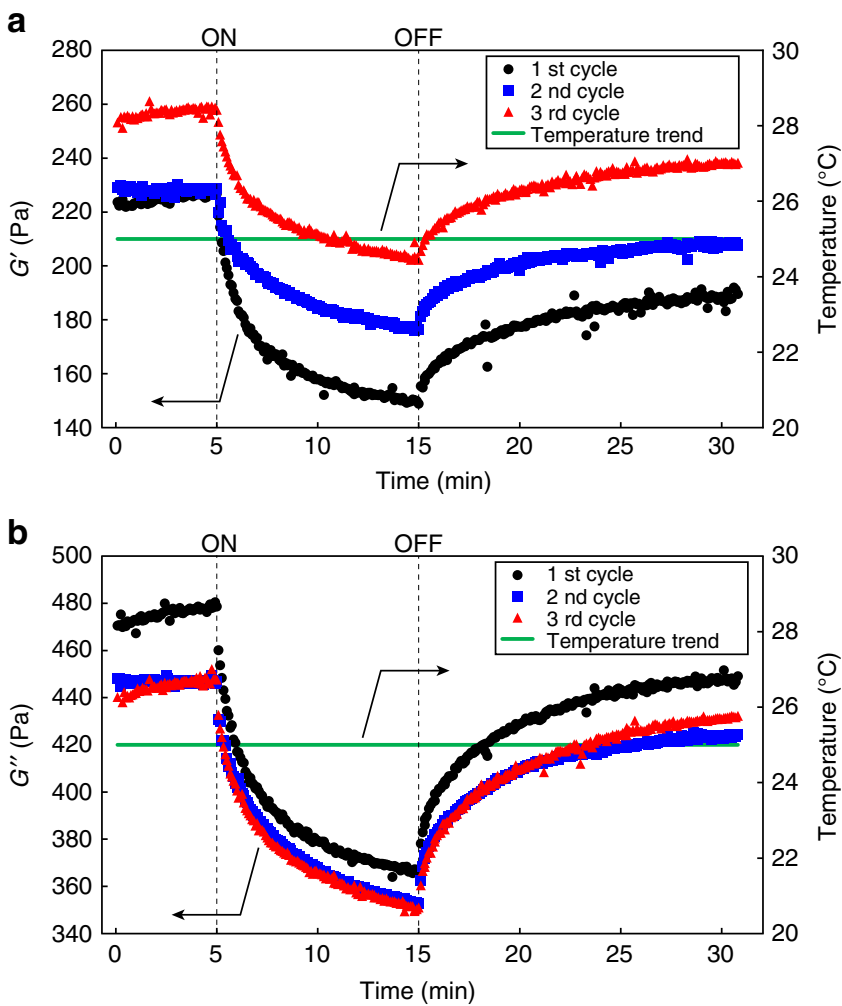

Fig. 5 Rheological properties upon repetitive UV irradiations. Timedependent plots of $\mathbf{a} G^{\prime}$ and $\mathbf{b} G^{\prime \prime}$ for network-PDMS $\mathbf{S}_{\text {HABI }}$ upon repeating UV irradiation cycles (1st cycle: black circle, 2nd cycle: blue square, and 3rd cycle: red triangle) with monitoring temperature (green line). The starting (ON) and terminating (OFF) times of UV irradiation were indicated with dashed lines

during the measurements was negligible (Fig. 5, green line). DMA analysis of network-PBA $\mathbf{A}_{\text {HABI }}$ under irradiating UV at $50{ }^{\circ} \mathrm{C}$ likewise showed repetitive decreases and increases of both of $G^{\prime}$ (Supplementary Fig. 12a) and $G^{\prime \prime}$ (Supplementary Fig. 12b), indicating that the present repeatable MAT-based IRLNC has a certain level of generality.

Meanwhile, DMA analysis of network-PDMS HABI $_{\text {showed }}$ higher $G^{\prime \prime}$ than $G^{\prime}$ irrespective of UV irradiation, which is more typical for liquid materials. From this characteristic and the actual

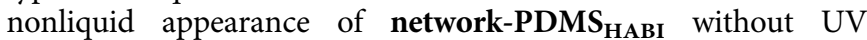
irradiation (Supplementary Movie 2), two reasons can be considered for the present IRLNC. One is high-complex viscosity

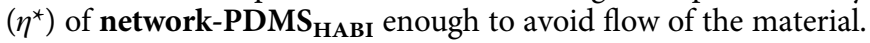
The other is the existence of crossovers with the frequencydependent curves of $G^{\prime}$ and $G^{\prime \prime}$. In fact, various polymer materials show frequency dependence of $G^{\prime}$ and $G^{\prime \prime}$ and whether we should define the materials as liquid or nonliquid relies on a time scale for observing the phenomenon as recognized in the pitch drop experiment started from 1927 and still continues ${ }^{38}$. Moreover, Sheiko and coworkers reported unique dependence of $G^{\prime}$ and $G^{\prime \prime}$ on frequency with solvent-free supersoft and superelastic bottlebrushes composed either of PBA or PDMS ${ }^{39}, 40$. Thus, we further examined frequency dependence of $G^{\prime}$ and $G^{\prime \prime}$ with

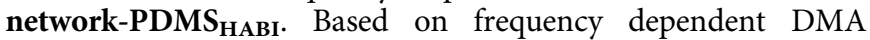
measurements for network-PDMS $\mathbf{H A B I}_{\mathrm{HA}}$, it was revealed that the plots of $G^{\prime \prime}$ were always greater than those of $G^{\prime}$ irrespective of UV irradiation in the experiment range (Fig. 6a) and $\eta^{*} s$ at the corresponding frequencies were $\sim 150 \mathrm{~Pa} s$ (Fig. 6b). Given that $\eta^{\star} \mathrm{s}$ of commercial linear PDMS melts were in the range of $1.0-1.5 \mathrm{~Pa} s$ at a similar frequency range ${ }^{41}$, the measured $\eta^{\star} s$ for
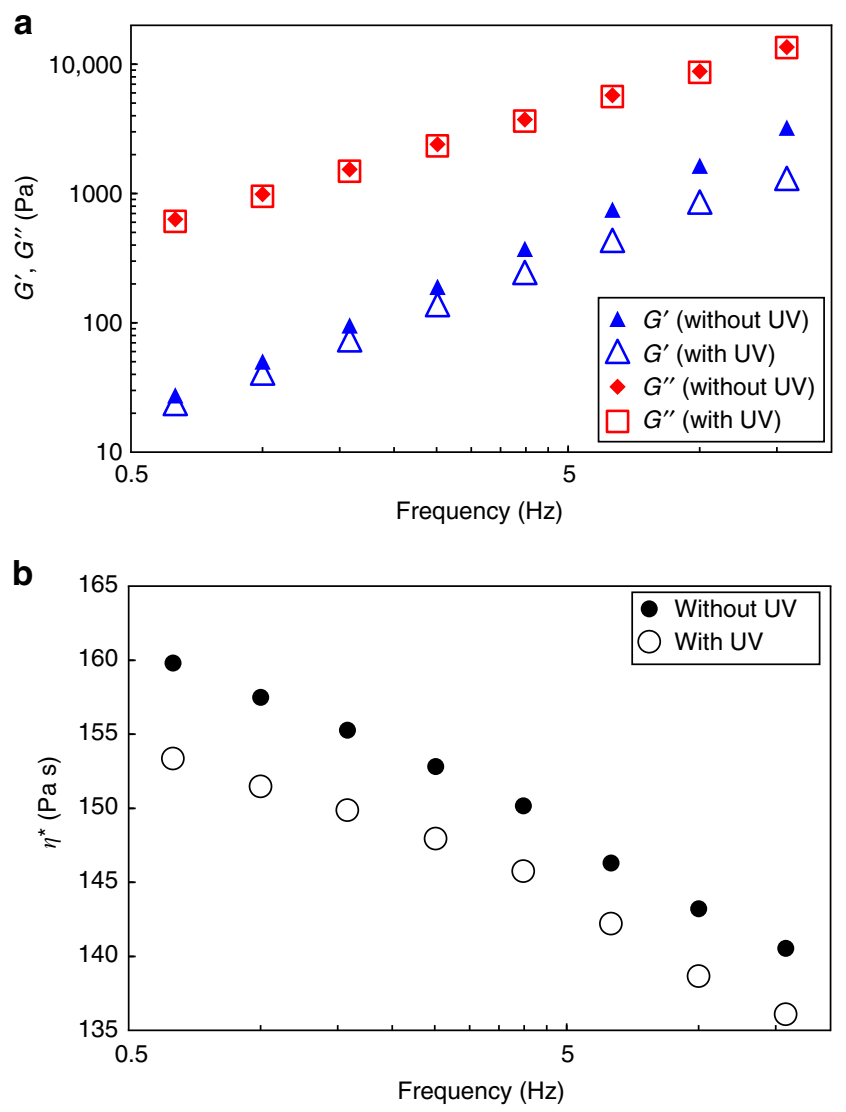

Fig. 6 Frequency dependence on rheological properties with and without UV irradiation. a Frequency-dependent plots of $G^{\prime}$ and $G^{\prime \prime}$ for networkPDMS $_{\text {HABI }}$ ( $G^{\prime}$ without UV: blue triangle, $G^{\prime}$ with UV: blue open triangle, $G^{\prime \prime}$ without UV: red diamond, G" with UV: red open square). b Frequencydependent plots of $\eta^{\star}$ without (black circle) and with (black open circle) UV irradiation

network-PDMS $S_{\text {HABI }}$ were roughly hundredfold greater than those of such PDMS melts. The decreased amounts of $G^{\prime}$ and $G^{\prime \prime}$ at the frequency around $3 \mathrm{~Hz}$ did not correspond to that appeared in the temperature-dependent measurement (Fig. 5) likely due to the difference in thickness of the samples. However, the frequency dependent DMA measurements also revealed that the decrease of $G^{\prime}$ upon UV irradiation was more prominent than that of $G^{\prime \prime}$ (Fig. 6a).

\section{Discussion}

IRLNC of polymeric materials relying on repeatable MAT between star and network architectures was demonstrated. The key for the present repeatable MAT was cleavage and reformation of the imidazole-imidazole covalent bond in HABI, which enabled prompt IRLNC in response to UV. The mechanism for the present IRLNC was further examined by DMA studies. Generally, the existence of network structure is primarily responsible for exhibiting elasticity and network-PDMS HABI $_{\mathbf{H A}}$ showed greater shift of $G^{\prime}$ than $G^{\prime \prime}$ upon UV irradiation. Therefore, the decrease of $\eta^{*}$ or $G^{\prime}$ by UV irradiation presumably caused the photo-triggered solvent-free IRLNC. Moreover, IRLNC methodology is, in principle, general as long as the parent star-shaped polymers are liquid. Therefore, the described repeatable MAT-based IRLNC and photo-triggered repeatable metamorphosis of polymers open the door to soft materials for use in various fields such as recyclable and deformable structural 
materials and adhesives, including human body-related applications.

\section{Methods}

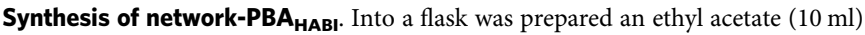
solution of star-PBA $\mathbf{L}_{\text {Lophine }}(170 \mathrm{mg}, 0.174 \mathrm{mmol}$ for end groups), and an aqueous solution $(10 \mathrm{ml})$ containing potassium ferricyanide $(2.86 \mathrm{~g}, 8.7 \mathrm{mmol})$ and potassium hydroxide $(488 \mathrm{mg}, 8.7 \mathrm{mmol})$ was added. The mixture was stirred at room temperature for $60 \mathrm{~min}$. The aqueous layer was separated and extracted with ethyl acetate. The combined ethyl acetate phases were washed with water, dried over $\mathrm{MgSO}_{4}$, and evaporated. After drying under reduced pressure, an elastic solid poorly soluble to organic solvents (network-PBA $\mathbf{A A B I}_{\mathbf{H A}}$ ) was obtained. The yield was $142 \mathrm{mg} .{ }^{1} \mathrm{H}$ NMR $\left(500 \mathrm{MHz}, \mathrm{CDCl}_{3}\right) \delta$ p.p.m. $0.88\left(\mathrm{~s},-\mathrm{CH}_{2} \mathrm{CH}_{3}\right), 1.08(\mathrm{~s},-\mathrm{C}$ $\left.\left(\mathrm{CH}_{3}\right)_{2}-\right), 1.21-2.65\left(\mathrm{~m},-\mathrm{CH}_{2} \mathrm{CH}\left(\mathrm{COO}^{n} \mathrm{Bu}\right)-,-\mathrm{CH}_{2} \mathrm{CH}_{2} \mathrm{CH}_{3}\right), 4.05(\mathrm{~m}$, $\left.-\mathrm{COOCH}_{2}-\right)$, $5.12\left(\mathrm{~m}\right.$, triazole- $\left.\mathrm{CH}_{2} \mathrm{OAr}\right), 5.38\left(\mathrm{~m},-\mathrm{CH}_{2} \mathrm{CH}\left(\mathrm{COO}^{n} \mathrm{Bu}\right)\right.$-triazole), $6.85-7.93\left(-\mathrm{CH}_{2} \mathrm{OAr} H\right) \cdot M_{\mathrm{n}}(\mathrm{RI})=4300, M_{\mathrm{p}}(\mathrm{RI})=7200, M_{\mathrm{w}} / M_{\mathrm{n}}=2.34$.

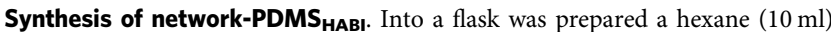
solution of star-PDMS Lophine $(1.35 \mathrm{~g}, 0.45 \mathrm{mmol}$ for end groups), and an aqueous solution $(30 \mathrm{ml})$ containing potassium ferricyanide $(7.41 \mathrm{~g}, 22.5 \mathrm{mmol})$ and potassium hydroxide $(1.26 \mathrm{mg}, 22.5 \mathrm{mmol})$ was added. The mixture was stirred at room temperature for $60 \mathrm{~min}$. The aqueous layer was separated and extracted with hexane. The combined hexane phases were washed with water, dried over $\mathrm{MgSO}_{4}$, and evaporated. After drying under reduced pressure, an elastic solid poorly soluble to organic solvents (network-PDMS HABI $_{\text {) }}$ was obtained. The yield was $1.32 \mathrm{~g} .{ }^{1} \mathrm{H}$ NMR $\left(500 \mathrm{MHz}, \mathrm{CDCl}_{3}\right) \delta$ p.p.m. $0.03-0.53\left(\mathrm{~s},-\mathrm{CH}_{3}\right), 0.61$ (s, $-\mathrm{CH}_{2} \mathrm{CH}_{2} \mathrm{CH}_{2} \mathrm{OAr}$ ), 1.75 (s, $-\mathrm{CH}_{2} \mathrm{CH}_{2} \mathrm{CH}_{2} \mathrm{OAr}$ ), 3.45-3.89 (m, - $\mathrm{CCH}_{2} \mathrm{O}-,-\mathrm{CH}_{2} \mathrm{CH}_{2} \mathrm{CH}_{2} \mathrm{OAr}$ ), $7.00-8.22(\mathrm{~m}, \mathrm{Ar} H) . M_{\mathrm{n}}(\mathrm{RI})=6100, M_{\mathrm{p}}(\mathrm{RI})=11200, M_{\mathrm{w}} / M_{\mathrm{n}}=2.34$.

UV irradiation experiments. UV irradiation experiments were performed using a Hamamatsu LIGHTNING CURE LC8 L9588 model with a Hamamatsu A1001435-0110 light guide. A Hamamatsu A9616-07 filter was used for efficiently transmitting only the UV light around $365 \mathrm{~nm}\left(150 \mathrm{~mW} / \mathrm{cm}^{2}\right)$. UV irradiation to the bulk network-PBA $\mathbf{A}_{\text {HABI }}$ was performed on the slide glass heated at $50{ }^{\circ} \mathrm{C}$ with hot plate. For concentration-dependent experiments, UV was directly irradiated to the quartz cells containing THF dispersions of network-PBA $\mathbf{A}_{\mathbf{H A B I}}(1,5,10,50$, and $100 \mathrm{mg} / \mathrm{ml}$ ). Further, UV irradiation to the bulk network-PDMS ${ }_{\text {HABI }}$ inside the vial was performed at $25^{\circ} \mathrm{C}$.

Rheological analyses. Rheological analyses under the irradiation of UV (365 nm, $150 \mathrm{~mW} / \mathrm{cm}^{2}$ ) were performed on an Anton Paar MCR 302 rheometer equipped with a UV curing system and a Pertier temperature control device. Timedependent analyses of storage modulus $\left(G^{\prime}\right)$ and loss modulus $\left(G^{\prime \prime}\right)$ were conducted using a parallel plate with a diameter of $12 \mathrm{~mm}$ at the frequency of $3 \mathrm{~Hz}$ for the samples with the thickness of $0.5 \mathrm{~mm}$. Temperatures of the parallel plate were set to $50{ }^{\circ} \mathrm{C}$ for network-PBA $\mathbf{H A B I}_{\mathrm{HA}}$ and to $25^{\circ} \mathrm{C}$ for network-PDMS $\mathrm{HABI}_{\mathrm{H}}$ and were monitored during the measurements. Each time-dependent measurement was conducted for $30 \mathrm{~min}$ and then the sample was held sufficient time to reach equilibrium state before starting the following measurements. For frequencydependent $G^{\prime}$ and $G^{\prime \prime}$ measurements, the network-PDMS HABI $_{\text {sample with the }}$ thickness of $0.12 \mathrm{~mm}$ was employed.

Data availability. The data that support the findings of this study are available from the corresponding authors upon reasonable request.

Received: 6 October 2016 Accepted: 16 July 2017

Published online: 11 September 2017

\section{References}

1. Clouse, R. M., Linchangco, G. V., Kerr, A. M., Reid, R. W. \& Janies, D. A. Phylotranscriptomic analysis uncovers a wealth of tissue inhibitor of metalloproteinases variants in echinoderms. R. Soc. Open Sci. 2, 150377 (2015).

2. Tamori, M. et al. Ultrastructural changes associated with reversible stiffening in catch connective tissue of sea cucumbers. PLOS ONE 11, e0155673 (2016).

3. Capadona, J. R., Shanmuganathan, K., Tyler, D. J., Rowan, S. J. \& Weder, C. Stimuli-responsive polymer nanocomposites inspired by the sea cucumber dermis. Science 319, 1370-1374 (2008)

4. Akiyama, H. \& Yoshida, M. Photochemically reversible liquefaction and solidification of single compounds based on a sugar alcohol scaffold with multi Azo-arms. Adv. Mater. 24, 2353-2356 (2012).

5. Akiyama, H. et al. Photochemically reversible liquefaction and solidification of multiazobenzene sugar-alcohol derivatives and application to reworkable adhesives. ACS Appl. Mater. Interfaces 6, 7933-7941 (2014).

6. Akiyama, H. et al. Photochemical liquid-solid transitions in multi-dye compounds. Mol. Cryst. Liq. Cryst. 604, 64-70 (2014).
7. Hoshino, M. et al. Crystal melting by light: X-ray crystal structure analysis of an Azo crystal showing photoinduced crystal-melt transition. J. Am. Chem. Soc. 136, 9158-9164 (2014).

8. Norikane, Y., Hirai, Y. \& Yoshida, M. Photoinduced isothermal phase transitions of liquid-crystalline macrocyclic azobenzenes. Chem. Commun. 47, 1770-1772 (2011).

9. Norikane, Y. et al. Photoinduced crystal-to-liquid phase transitions of azobenzene derivatives and their application in photolithography processes through a solid-liquid patterning. Org. Lett. 16, 5012-5015 (2014).

10. Uchida, E. et al. Control of the orientation and photoinduced phase transitions of macrocyclic azobenzene. Chem. Eur. J 19, 17391-17397 (2013).

11. Norikane, Y. et al. Photoinduced phase transitions in rod-shaped azobenzene with different alkyl chain length. J. Photopolym. Sci. Technol. 29, 149-157 (2016).

12. Norikane, Y., Tanaka, S. \& Uchida, E. Azobenzene crystals swim on water surface triggered by light. CrystEngComm. 18, 7225-7228 (2016).

13. Uchida, E., Azumi, R. \& Norikane, Y. Light-induced crawling of crystals on a glass surface. Nat. Commun. 6, 7310 (2015).

14. Zhou, H. et al. Photoswitching of glass transition temperatures of azobenzenecontaining polymers induces reversible solid-to-liquid transitions. Nat. Chem. 9, 145-151 (2017).

15. Akiyama, H., Fukata, T., Yamashita, A., Yoshida, M. \& Kihara, H. Reworkable adhesives composed of photoresponsive azobenzene polymer for glass substrates. J. Adhes. 93, 823-830 (2017).

16. Hadjichristidis, N., Hirao, A., Tezuka, Y. \& Du Prez, D. Complex macromolecular architectures: synthesis characterization and self assembly (Wiley, 2011).

17. Nishimori, H., Tatsumisago, M. \& Minami, T. Growth mechanism of large monodispersed silica particles prepared from tetraethoxysilane in the presence of sodium dodecyl sulfate. J. Sol-Gel Sci. Technol. 9, 25-31 (1997).

18. Aoki, D., Uchida, S. \& Takata, T. Star/linear polymer topology transformation facilitated by mechanical linking of polymer chains. Angew. Chem. Int. Ed. 54, 6770-6774 (2015).

19. Ogawa, T., Nakazono, K., Aoki, D., Uchida, S. \& Takata, T. Effective approach to cyclic polymer from linear polymer: synthesis and transformation of macromolecular [1]rotaxane. ACS Macro Lett. 4, 343-347 (2015).

20. Ogawa, T., Usuki, N., Nakazono, K., Koyama, Y. \& Takata, T. Linear-cyclic polymer structural transformation and its reversible control using a rational rotaxane strategy. Chem. Commun. 51, 5606-5609 (2015).

21. Valentina, S., Ogawa, T., Nakazono, K., Aoki, D. \& Takata, T. Efficient synthesis of cyclic block copolymers by rotaxane protocol by linear/cyclic topology transformation. Chem. Eur. J 22, 8759-8762 (2016).

22. Yamamoto, T., Yagyu, S. \& Tezuka, Y. Light- and heat-triggered reversible linear-cyclic topological conversion of telechelic polymers with anthryl end groups. J. Am. Chem. Soc. 138, 3904-3911 (2016).

23. Telitel, S. et al. Introduction of self-healing properties into covalent polymer networks via the photodissociation of alkoxyamine junctions. Polym. Chem. 5, 921-930 (2014).

24. Sun, H. et al. Macromolecular metamorphosis via stimulus-induced transformations of polymer architecture. Nat. Chem. 9, 817-823 (2017).

25. Maeda, T., Otsuka, H. \& Takahara, A. Dynamic covalent polymers: reorganizable polymers with dynamic covalent bonds. Prog. Polym. Sci. 34, 581-604 (2009).

26. Hillewaere, X. K. D. \& Du Prez, F. E. Fifteen chemistries for autonomous external self-healing polymers and composites. Prog. Polym. Sci. 49-50, 121-153 (2015).

27. Hayashi, T. \& Maeda, K. Preparation of a new phototropic substance. Bull. Chem. Soc. Jpn. 33, 565-566 (1960).

28. Coraor, G. R. et al. Reactions of triarylimidazolyl free radicals. J. Org. Chem. 36, 2267-2272 (1971).

29. Tanino, H., Kondo, T., Okada, K. \& Goto, T. Structures of three isomeric dimers of 2,4,5-triphenylimidazolyl. Bull. Chem. Soc. Jpn. 45, 1474-1480 (1972).

30. Goto, T., Tanino, H. \& Kondo, T. Photochemical and thermal interconversions of three dimers of 2,4,5-triphenylimidazoryl (lophyl). Chem. Lett. 9, 431-434 (1980).

31. Iwamura, T. \& Sakaguchi, M. A novel de-cross-linking system from crosslinked polymer to linear polymer utilizing pressure or visible light irradiation. Macromolecules. 41, 8995-8999 (2008).

32. Hayashi, T., Maeda, K., Shida, S. \& Nakada, K. A new phototropic substance and its ESR. J. Chem. Phys. 32, 1568-1568 (1960).

33. Gong, W.-L., Zhang, G.-F., Li, C., Aldred, M. P. \& Zhu, M.-Q. Design, synthesis and optical properties of a green fluorescent photoswitchable hexaarylbiimidazole (HABI) with non-conjugated design. RSC Adv 3, 9167-9170 (2013).

34. Kikuchi, A., Iyoda, T. \& Abe, J. Electronic structure of light-induced lophyl radical derived from a novel hexaarylbiimidazole with $\pi$-conjugated chromophore. Chem. Commun. 38, 1484-1485 (2002).

35. Kishimoto, Y. \& Abe, J. A fast photochromic molecule that colors only under UV Light. J. Am. Chem. Soc. 131, 4227-4229 (2009). 
36. Takasaki, M., Hiroki, K. \& Iwamura, T. Synthesis of organic-inorganic polymer hybrids from acrylate polymer having a triphenylimidazole moiety via $\pi-\pi$ interactions. Polym. Bull. 72, 645-651 (2015).

37. Lohmeijer, B. G. G. et al. Organocatalytic living ring-opening polymerization of cyclic carbosiloxanes. Org. Lett. 8, 4683-4686 (2006).

38. Edgeworth, R., Dalton, B. J. \& Parnell, T. The pitch drop experiment. Eur. J. Phys. 5, 198-200 (1984)

39. Neugebauer, D., Zhang, Y., Pakula, T., Sheiko, S. S. \& Matyjaszewski, K. Densely-grafted and double-grafted PEO brushes via ATRP. A route to soft elastomers. Macromolecules. 36, 6746-6755 (2003).

40. Daniel, W. F. M. et al. Solvent-free, supersoft and superelastic bottlebrush melts and networks. Nat. Mater. 15, 183-189 (2016).

41. Romoscanu, A. I., Sayir, M. B., Häusler, K. \& Servais, C. High frequency probe for the measurement of the complex viscosity of liquids. Meas. Sci. Technol. 14, 451-462 (2003).

\section{Acknowledgements}

We are grateful to Mr. Yuichi Shinozaki and Mr. Yasuhito Kajita at Anton Paar Japan K.K. for our access to the DMA apparatus and kind support for the analyses. This work was supported partly by JSPS KAKENHI (Grant Numbers 16K14074 S.H. and 16H04032 T.T.) and Izumi Science and Technology Foundation (S.H.).

\section{Author contributions}

S.H. designed the work and performed the experiments. S.H. and T.T. wrote the manuscript.

\section{Additional information}

Supplementary Information accompanies this paper at doi:10.1038/s41467-017-00679-1.

Competing interests: The authors declare no competing financial interests.

Reprints and permission information is available online at http://npg.nature.com/ reprintsandpermissions/

Publisher's note: Springer Nature remains neutral with regard to jurisdictional claims in published maps and institutional affiliations.

cc (i) Open Access This article is licensed under a Creative Commons Attribution 4.0 International License, which permits use, sharing, adaptation, distribution and reproduction in any medium or format, as long as you give appropriate credit to the original author(s) and the source, provide a link to the Creative Commons license, and indicate if changes were made. The images or other third party material in this article are included in the article's Creative Commons license, unless indicated otherwise in a credit line to the material. If material is not included in the article's Creative Commons license and your intended use is not permitted by statutory regulation or exceeds the permitted use, you will need to obtain permission directly from the copyright holder. To view a copy of this license, visit http://creativecommons.org/ licenses/by/4.0/.

(C) The Author(s) 2017 